\title{
A New Approach for Selecting Slightly Non-homogeneous Vendors
}

\author{
Reza Farzipoor Saen \\ Department of Industrial Management, Management and Accounting Faculty, Islamic Azad \\ University-Karaj Branch, Karaj, Iran, P. O. Box: 31485-313
}

Tel: 0098 (261) 4418144-6

Fax: 0098 (261) 4418156

Email: farzipour@yahoo.com

\begin{abstract}
Purpose - The purpose of this paper is to propose a straightforward model for selecting slightly nonhomogeneous vendors.

Design/methodology/approach - In this paper the use of the interval Data Envelopment Analysis (DEA) is suggested. The bounds of intervals are constant and can be obtained by various estimation techniques. The interval DEA model provides for the Decision Making Units (DMUs) with missing values a lower and an upper bound of their efficiency score corresponding to their most favorable and unfavorable option.
\end{abstract}

Findings - In this paper a method for selecting slightly non-homogeneous vendors was proposed. Employing the proposed method, practical difficulties for vendor selection are largely reduced. This method does not exclude any vendor from the selection problem. For all the vendors it provides bounds of the efficiency scores depended on the particular data values that the vendors with missing data assign within the intervals so to maximize their efficiency score.

Practical implications - The proposed model considers slightly-nonhomogeneous situation for vendor selection. The proposed approach is driven by multiple criteria. The joint consideration of multiple criteria in slightly-nonhomogeneous environment helps managers select vendors using a comprehensive approach that goes beyond just purchase costs.

Originality/value - To the best of author's knowledge, there is not any reference that discusses the problem of slightly non-homogeneous vendor selection with respect to interval mathematics.

Keywords Vendor selection, Slightly non-homogeneous vendors, Data envelopment analysis, Interval data, Missing values

Paper type Research paper

\section{Introduction}

Managing the purchasing task in the supply chain has been a challenge in the last decade for many corporations. The need to gain a global competitive edge on the supply side has increased substantially. Particularly for companies who spend a high percentage of their sales revenue on parts and material supplies, and whose material costs represent a larger portion of total costs, savings from supplies are of particular importance. These, strongly urge for a more systematic and transparent approach to purchasing decision making, especially regarding the area of vendor selection. Selecting the vendors significantly reduces the purchasing cost and improves corporate competitiveness, which is why many experts believe that the vendor selection is the most important activity of a purchasing department. Vendor selection is the process by which vendors are reviewed, evaluated, and chosen to become part of the company's supply chain. Shin, Collier and Wilson (2000) argue that several important factors have caused the current shift to single sourcing or a reduced vendor base. First, multiple sourcing prevents vendors from achieving the economies of scale based on order volume and 
learning curve effect. Second, multiple vendor system can be more expensive than a reduced vendor base. For instance, managing a large number of vendors for a particular item directly increases costs, including the labor and order processing costs to managing multiple source inventories. Meanwhile multiple sourcing lowers overall quality level because of the increased variation in incoming quality among vendors. Third, a reduced vendor base helps eliminate mistrust between buyers and vendors due to lack of communication. Fourth, worldwide competition forces firms to find the best vendors in the world.

The assumption of classical vendor selection models is based on the principle that vendors consume common inputs to supply common outputs.

In spite of this assumption in many applications some vendors do not comprehensively consume common inputs to comprehensively supply common outputs. For instance, to select a vendor most of inputs and outputs (selection criteria) of vendors are common, but there are a few input(s) and/or output(s) for some vendors that may not be common to all. In a vendor evaluation example that buyer consumes two types of materials such as type A and type B. A vendor may not supply type B. To evaluate this vendor, considering cost as an input, cost of type B for the vendor is meaningless. It is clear that zero value allocation for this type of input, causes relative efficiency of the vendor, to increase unrealistically. In other words, to evaluate the relative efficiency of vendors, all the vendors may not have identical functions. In this case, it is not acceptable saying that the vendors which do not supply material of type B, are not comparable with the vendors which supply material of type B. Meanwhile, allocating zero value to vendors that do not supply material of type $B$, is not fair. Generally, zero allocation to outputs and inputs of some vendors, makes the efficiency evaluation unfair. That is zero allocation to output, may make a vendor inefficient, on the other hand, zero allocation to input, may make a vendor efficient, unrealistically.

The objective of this paper is to propose a straightforward model for selecting slightly nonhomogeneous vendors. The proposed model is based on Data Envelopment Analysis (DEA).

This paper proceeds as follows. In Section 2, literature review is presented. Proposed model for selecting vendors is introduced in Section 3. Numerical example and managerial implications are discussed in Sections 4 and 5, respectively. Concluding remarks are illustrated in Section 6.

\section{Literature review}

Some approaches have been used for vendor selection in the past. Table 1 categorizes the reviewed papers based on applied techniques.

However, all the references in Table 1 rely on the assumption of complete homogeneity of vendors and do not consider the slightly non-homogeneous vendors.

Recently, to determine the relative efficiency of slightly non-homogeneous vendors, Farzipoor Saen (2007) developed an algorithm that is based on AHP and Chance-Constrained Data Envelopment Analysis (CCDEA). However, the proposed algorithm has five steps and it is computational burden.

To the best of author's knowledge, there is not any reference that discusses the problem of slightly non-homogeneous vendor selection in a straightforward manner. 
Table 1. Classification of vendor selection techniques

\begin{tabular}{|c|c|}
\hline Technique name & References \\
\hline Cost-based model & Youssef, Zairi and Mohnaty (1996) \\
\hline Expert systems & Vokurka, Choobineh and Vadi (1996), Kwong, Ip, and Chan (2002) \\
\hline $\begin{array}{l}\text { Data envelopment } \\
\text { analysis (DEA) }\end{array}$ & $\begin{array}{l}\text { Weber (1996), Braglia and Petroni (2000), Weber, Current and Desai (2000), Liu, Ding } \\
\text { and Lall (2000), Forker and Mendez (2001), Ross and Droge (2002), Talluri, } \\
\text { Narasimhan and Nair (2006) }\end{array}$ \\
\hline $\begin{array}{l}\text { Analytic Hierarchy } \\
\text { Process (AHP) }\end{array}$ & $\begin{array}{l}\text { Bhutta and Huq (2002), Kahraman, Cebeci and Ulukan (2003), Çebi and Bayraktar } \\
\text { (2003), Wang, Huang and Dismukes (2004), Liu and Hai (2005), Xia and Wu (2007) }\end{array}$ \\
\hline Integer programming & $\begin{array}{l}\text { Dahel (2003), Ghodsypour and O Brien (2001), Talluri and Baker (2002), Ip, Yung and } \\
\text { Wang (2004) }\end{array}$ \\
\hline Dual-Matrix approach & Chandra, Chen and Chen (2005) \\
\hline Goal programming & $\begin{array}{l}\text { Karpak, Kumcu and Kasuganti (2001), Talluri and Narasimhan (2003), Kumar, Vrat } \\
\text { and Shankar (2004), Hajidimitriou and Georgiou (2002) }\end{array}$ \\
\hline Genetic algorithms & Sha and Che (2006) \\
\hline $\begin{array}{l}\text { Artificial } \\
\text { networks }\end{array}$ & Choy, Lee and Lo (2002) \\
\hline Factor analysis & Lasch and Janker (2005) \\
\hline $\begin{array}{l}\text { Fuzzy mathematical } \\
\text { programming }\end{array}$ & $\begin{array}{l}\text { Ohdar and Ray (2004), Lin and Chen (2004), Chang, Wang and Wang (2006), Chen, } \\
\text { Lin and Huang (2006) }\end{array}$ \\
\hline
\end{tabular}

\section{Proposed model for selecting vendors}

For those slightly non-homogeneous vendors (Decision Making Units (DMUs)) lacking one or some feature (input and/or output), the contribution with respect to the lacking factor(s) is considered as missing value(s). Fundamental assumptions of the original DEA are that the inputs and outputs are measured with crisp positive values on a ratio scale and all the data required are available. However, in many applications including slightly non-homogeneous vendor selection problem, the efficiency evaluation of the DMUs has to take into account missing values for some inputs and outputs. Replacement of missing values by approximations in the form of intervals in which the unknown missing values are likely to belong is proposed. The case of missing values in DEA models have been examined in the literature in different ways. Some approaches use imputation techniques to estimate exact approximations of the missing values (for example, average value of the other DMUs) (Cooper, Seiford and Tone (1999)). Smirlis, Maragos and Despotis (2006) proposed the use of the interval DEA and particularly the approach introduced by Despotis and Smirlis (2002). However, as Wang, Greatbanks and Yang (2005) indicated, their model used variable production frontiers, i.e. different constraint sets, to measure the efficiencies of DMUs, which made them lack of comparability.

In this paper the use of the interval DEA is suggested. The bounds of intervals are constant and can be obtained by various estimation techniques. The interval DEA model provides for the DMUs with missing values a lower and an upper bound of their efficiency score corresponding to their most favorable and unfavorable option.

To introduce the model, Table 2 lists the nomenclature used to formulate the problem under consideration. 
Table 2. Nomenclature

\begin{tabular}{|l|}
\hline Problem parameters \\
$j=1, \ldots, n$ collection of vendors (DMUs) \\
DMU $_{o}=$ the DMU under investigation \\
$r=1, \ldots, s \quad$ the set of outputs \\
$i=1, \ldots, m$ the set of inputs \\
$y_{r j}=$ the $r$ th output of $j$ th DMU \\
$x_{i j}=$ the $i$ th input of $j$ th DMU \\
$y_{r j o}^{U}=$ upper bound of $r$ th outputs of the $\mathrm{DMU}_{o}$ under investigation \\
$y_{r j o}^{L}=$ lower bound of $r$ th outputs of the $\mathrm{DMU}_{o}$ under investigation \\
$x_{i j o}^{U}=$ upper bound of $i$ th inputs of the $\mathrm{DMU}_{o}$ under investigation \\
$x_{i j o}^{L}=$ lower bound of $i$ th inputs of the $\mathrm{DMU}_{o}$ under investigation \\
$x_{i j}^{L}=$ lower bound \\
$y_{r j}^{U}=$ upper bound \\
$\theta_{j o}^{U}=$ the best possible relative efficiency achieved by DMU \\
$\theta_{j o}^{L}=$ the lower bound of the best possible relative efficiency of $\mathrm{DMU}_{o}$ \\
$\varepsilon=$ the non-Archimedean infinitesimal \\
Decision variables \\
$u_{r}=$ weight of the $r$ th output \\
$v_{i}=$ weight of the $i$ th input
\end{tabular}

Suppose that there are $n$ vendors (DMUs) to be evaluated. Each DMU consumes $m$ inputs to produce $s$ outputs. In particular, $\mathrm{DMU}_{j}$ consumes amounts $X_{j}=\left\{\mathrm{X}_{\mathrm{ij}}\right\}$ of inputs $(i=1, \ldots, m)$ and produces amounts $Y_{j}=\left\{y_{r j}\right\}$ of outputs $(r=1, \ldots, s)$. Unlike the original DEA model, the interval DEA assumes that some of the crisp input $x_{i j}$ and output $y_{r j}$ values are not known and for them, it is only known that they lie within bounded intervals, i.e. $x_{i j} \in\left[x_{i j}^{L}, x_{i j}^{U}\right]$ and $y_{r j} \in\left[y_{r j}^{L}, y_{r j}^{U}\right]$, with the upper and lower bounds of the intervals $x_{i j}^{L}, x_{i j}^{U}, y_{r j}^{L}, y_{r j}^{U}$ to be strictly positive constants.

In order to deal with such a situation, the following pair of linear programming models has been developed to generate the upper and lower bounds of interval efficiency for each DMU (Wang, Greatbanks and Yang (2005)): 


$$
\begin{aligned}
& \operatorname{Max} \theta_{j o}^{U}=\sum_{r=1}^{s} u_{r} y_{r j_{o}}^{U} \\
& \text { s.t. } \\
& \sum_{i=1}^{m} v_{i} x_{i j_{o}}^{L}=1, \\
& \sum_{r=1}^{s} u_{r} y_{r j}^{U}-\sum_{i=1}^{m} v_{i} x_{i j}^{L} \leq 0, \quad j=1, \cdots, n \\
& u_{r}, v_{i} \geq \varepsilon \quad \forall r, i . \\
& \operatorname{Max}_{j o}^{L}=\sum_{r=1}^{s} u_{r} y_{r j_{o}}^{L} \\
& s . t . \\
& \sum_{i=1}^{m} v_{i} X_{i j_{o}}^{U}=1, \\
& \sum_{r=1}^{s} u_{r} y_{r j}^{U}-\sum_{i=1}^{m} v_{i} x_{i j}^{L} \leq 0, \quad j=1, \cdots, n \\
& u_{r}, v_{i} \geq \varepsilon \quad \forall r, i .
\end{aligned}
$$

where $j_{o}$ is the DMU under evaluation (usually denoted by $\mathrm{DMU}_{o}$ ); $u_{r}$ and $v_{i}$ are the weights assigned to the outputs and inputs; $\theta_{j o}^{U}$ stands for the best possible relative efficiency achieved by $\mathrm{DMU}_{o}$ when all the DMUs are in the state of best production activity, while $\theta_{j o}^{L}$ stands for the lower bound of the best possible relative efficiency of $\mathrm{DMU}_{o}$. They constitute a possible best relative efficiency interval $\left[\theta_{j o}^{L}, \theta_{j o}^{U}\right] . \varepsilon$ is the non-Archimedean infinitesimal.

In order to judge whether a DMU is DEA efficient or not, the following definition is given.

Definition 1. A DMU, $\mathrm{DMU}_{o}$, is said to be DEA efficient if its best possible upper bound efficiency $\theta_{j o}^{U^{*}}=1$; otherwise, it is said to be DEA inefficient if $\theta_{j o}^{U^{*}}<1$.

Models (1) and (2) are able to handle interval data and estimate the efficiency bounds of the DMUs. Missing values of inputs/outputs can be replaced by estimations in the form of intervals. So intervals $\left[x_{i j}^{L}, x_{i j}^{U}\right],\left[y_{r j}^{L}, y_{r j}^{U}\right]$ can take the place of any missing input/output values $x_{i j}$ and $y_{r j}$ and thus form an interval data set. The bounds $x_{i j}^{L}, x_{i j}^{U}, y_{r j}^{L}, y_{r j}^{U}$, depending on the particular application, can be estimated by using different techniques: descriptive statistics, regression/extrapolation techniques, distance/proximity measurements, experts opinions, etc. When no estimation can be provided by any technique, the column minimum and maximum for the particular input-output may be used to form such an interval.

In the next section, a numerical example is presented.

\section{Numerical example}

The data set for this example has been taken from Farzipoor Saen (2007) and contains specifications on 12 vendors. Two inputs and 2 outputs are considered. Table 3 shows the data for 
inputs and outputs. As it is noticed, vendor 2 lacks one input, vendor ${ }_{4}$ also lacks one input, etc. Hence the comparison of these vendors with the others is not fair. For this, the proposed model is implemented. In Table 4, based on experts opinions, missing values of inputs/outputs are replaced by estimations in the form of intervals. The exact data are viewed as a special case of interval data with the lower and upper bounds being equal. Therefore, all the input and output data are now transformed into interval numbers and can be evaluated using interval DEA models. Using the interval DEA models (1) and (2), the rating results are obtained that have been shown in Table 5. The nonArchimedean infinitesimal was set to be $\varepsilon=10^{-10}$.

Table 3. Input and output vectors

\begin{tabular}{|c|c|c|c|c|}
\hline $\begin{array}{c}\text { Vendor } \\
\text { No. } \\
\text { (DMU) }\end{array}$ & $\mathrm{I}_{1}$ & $\mathrm{I}_{2}$ & $\mathrm{O}_{1}$ & $\mathrm{O}_{2}$ \\
\hline 1 & 5 & 3 & 8 & 3 \\
\hline 2 & - & 9 & 2 & 4 \\
\hline 3 & 3 & 4 & 9 & 0 \\
\hline 4 & 6 & - & 3 & 6 \\
\hline 5 & 2 & 6 & 4 & - \\
\hline 6 & - & 2 & 5 & 3 \\
\hline 7 & 3 & 3 & 4 & 6 \\
\hline 8 & - & 2 & - & 2 \\
\hline 9 & 4 & 0 & 5 & 3 \\
\hline 10 & 3 & 2 & 2 & - \\
\hline 11 & 2 & 5 & - & 4 \\
\hline 12 & 5 & 9 & 3 & 7 \\
\hline
\end{tabular}

Table 4. Replaced missing values by experts opinions

\begin{tabular}{|c|c|c|c|c|}
\hline $\begin{array}{c}\text { Vendor } \\
\text { No. } \\
(\mathrm{DMU})\end{array}$ & $\mathrm{I}_{1}$ & $\mathrm{I}_{2}$ & $\mathrm{O}_{1}$ & $\mathrm{O}_{2}$ \\
\hline 1 & 5 & 3 & 8 & 3 \\
\hline 2 & {$[3,7]$} & 9 & 2 & 4 \\
\hline 3 & 3 & 4 & 9 & 0 \\
\hline 4 & 6 & {$[4,6]$} & 3 & 6 \\
\hline 5 & 2 & 6 & 4 & {$[3,6]$} \\
\hline 6 & {$[3,5]$} & 2 & 5 & 3 \\
\hline 7 & 3 & 3 & 4 & 6 \\
\hline 8 & {$[3,8]$} & 2 & {$[3,5]$} & 2 \\
\hline 9 & 4 & 0 & 5 & 3 \\
\hline 10 & 3 & 2 & 2 & {$[2,7]$} \\
\hline 11 & 2 & 5 & {$[4,7]$} & 4 \\
\hline 12 & 5 & 9 & 3 & 7 \\
\hline
\end{tabular}

It can be seen from Table 5 that, with respect to definition 1, vendors 3, 5, 9, 10, and 11 are efficient and should be considered as the best vendors.

Table 5. The results 


\begin{tabular}{|c|c|}
\hline $\begin{array}{c}\text { Vendor } \\
\text { No. } \\
(\mathrm{DMU})\end{array}$ & {$\left[\theta_{j o}^{L}, \theta_{j o}^{U}\right]$} \\
\hline 1 & {$[.83, .83]$} \\
\hline 2 & {$[.24, .44]$} \\
\hline 3 & {$[1,1]$} \\
\hline 4 & {$[.44, .5]$} \\
\hline 5 & {$[.65,1]$} \\
\hline 6 & {$[.62, .91]$} \\
\hline 7 & {$[.97, .97]$} \\
\hline 8 & {$[.27, .85]$} \\
\hline 9 & {$[1,1]$} \\
\hline 10 & {$[.45,1]$} \\
\hline 11 & {$[.8,1]$} \\
\hline 12 & {$[.53, .53]$} \\
\hline
\end{tabular}

\section{Managerial implications}

Efficient Supply Chain Management (SCM) requires efficient vendor selection. Strategic management decisions impact all areas of a firm. Once such decisions are made, the criteria for making subsequent operational decisions must be re-examined. New strategic directions may require new criteria and a re-emphasis of the existing criteria used in making the operational decisions necessary to implement them. An important area of operational decision making is purchasing. One major aspect of the purchasing function is vendor selection. In today's competitive operating environment, it is impossible to successfully achieve low cost, high quality products without having satisfactory vendors. Thus, one of the most important purchasing decisions is the selection and maintenance of a competent group of vendors.

Purchasing materials have long been recognized as a multi-criteria problem. The joint consideration of multiple criteria complicates the selection decision, even in the case of experienced purchase managers, because competing vendors have different levels of success under multiple criteria. For example, the vendor with the lowest price in a given industry may not have the best delivery performance or product quality. Although the problem involving the multi-criteria nature of vendor selection has been solved, the emergence of a slightly-nonhomogeneous situation becomes a major obstacle for procurement managers in finding the best purchasing strategy. All the optimization models of SCM assume complete homogeneity of vendors. This is far beyond the real situation. In fact, in the real world, some vendors are slightly-nonhomogeneous.

The vendor selection approach developed in this paper includes a number of attractive features.

- The proposed model considers slightly-nonhomogeneous situation for vendor selection.

- Vendor selection is a straightforward process carried out by the proposed model and is computationally efficient and can be solved in a few seconds on a personal computer.

- The proposed model deals with slightly-nonhomogeneous situation in a direct manner.

- The proposed approach is driven by multiple criteria. The joint consideration of multiple criteria in slightly-nonhomogeneous environment helps managers select vendors using a comprehensive approach that goes beyond just purchase costs. 


\section{Concluding remarks}

Many practitioners and researchers have presented the advantages of supply chain management. In order to increase the competitive advantage, many companies consider that a well-designed and implemented supply chain system is an important tool. Under this condition, building on the closeness and long-term relationships between buyers and vendors is critical success factor to establish the supply chain system. Therefore, vendor selection problem becomes the most important issue to implement a successful supply chain system.

One of the assumptions of all the classical models of vendor selection is based on complete homogeneity of vendors, whereas this assumption in many cases cannot be generalized. In other words, some of the criteria are not common for all the vendors occasionally. In this paper a method for selecting slightly non-homogeneous vendors was proposed. Employing the proposed method, practical difficulties for vendor selection are largely reduced. This method does not exclude any vendor from the selection problem. For all the vendors it provides bounds of the efficiency scores depended on the particular data values that the vendors with missing data assign within the intervals so to maximize their efficiency score.

The problem considered in this study is at initial stage of investigation and much further researches can be done based on the results of this paper. Some of them are as follows:

- Similar research can be repeated for ranking the slightly non-homogeneous vendors.

- The other research can be repeated for dealing with ordinal data in the conditions that slightly-nonhomogeneous situations exist.

- Similar research can be repeated for vendor selection in the presence of both fuzzy data and slightly-nonhomogeneous situations.

- This study used the proposed model for vendor selection. It seems that more fields (e.g. technology selection, personnel selection, etc) can be applied.

\section{References}

Bhutta, K. S. and Huq, F. (2002), "Supplier selection problem: a comparison of the total cost of ownership and analytic hierarchy process approaches”, Supply Chain Management: An International Journal, Vol. 7 No. 3, pp. 126-135.

Braglia, M. and Petroni, A. (2000), "A quality assurance-oriented methodology for handling trade-offs in supplier selection”, International Journal of Physical Distribution \& Logistics Management, Vol. 30 No. 2, pp. 96-111.

Çebi, F. and Bayraktar, D. (2003), “An integrated approach for supplier selection”, Logistics Information Management, Vol. 16 No. 6, pp. 395-400.

Chandra, S., Chen, B. and Chan, W. M. (2005), "Supplier selection using dual-matrix approach in a JIT system", Proceedings of 14th International Conference for the International Association of Management of Technology, pp. 1-6.

Chang, S. L., Wang, R. C. and Wang, S. Y. (2006), “Applying fuzzy linguistic quantifier to select supply chain partners at different phases of product life cycle”, International Journal of Production Economics, Vol. 100 No. 2, pp. 348-359.

Chen, C. T., Lin, C. T. and Huang, S. F. (2006), "A fuzzy approach for supplier evaluation and selection in supply chain management”, International Journal of Production Economics, Vol. 102 No. 2, pp. 289-301. 
Choy, K. L., Lee, W. B. and Lo, V. (2002), "An intelligent supplier management tool for benchmarking suppliers in outsource manufacturing”, Expert Systems with Applications, Vol. 22 No. 3, pp. 213-224.

Cooper, W., Seiford, L. and Tone, K. (1999), "Data envelopment analysis: a comprehensive text with models, applications, references and DEA-solver software”, Kluwer Academic Publishers.

Dahel, N. E. (2003), "Vendor selection and order quantity allocation in volume discount environments”, Supply Chain Management: An International Journal, Vol. 8 No. 4, pp. 335-342.

Despotis, D. K. and Smirlis, Y. G. (2002), "Data envelopment analysis with imprecise data", European Journal of Operational Research, Vol. 140 No. 1, pp. 24-36.

Farzipoor Saen, R. (2007), “A new mathematical approach for suppliers selection: accounting for nonhomogeneity is important”, Applied Mathematics and Computation, Vol. 185 No. 1, pp. 84-95.

Forker, L. B. and Mendez, D. (2001), “An analytical method for benchmarking best peer suppliers”, International Journal of Operations \& Production Management, Vol. 21 No. 12/2, pp. 195-209.

Ghodsypour, S. H. and O'Brien, C. (2001), "The total cost of logistics in supplier selection, under conditions of multiple sourcing, multiple criteria and capacity constraint", International Journal of Production Economics, Vol. 73 No. 1, pp. 15-27.

Hajidimitriou, Y. A. and Georgiou, A. C. (2002), "A goal programming model for partner selection decisions in international joint ventures”, European Journal of Operational Research, Vol. 138 No. 3, pp. 649-662.

Ip, W. H., Yung, K. L. and Wang, D. (2004), “A branch and bound algorithm for sub-contractor selection in agile manufacturing environment”, International Journal of Production Economics, Vol. 87 No. 2, pp. 195-205.

Kahraman, C., Cebeci, U. and Ulukan, Z. (2003), “Multi-criteria supplier selection using fuzzy AHP”, Logistics Information Management, Vol. 16 No. 6, pp. 382-394.

Karpak, B., Kumcu, E. and Kasuganti, R. R. (2001), "Purchasing materials in the supply chain: managing a multi-objective task”, European Journal of Purchasing \& Supply Management, Vol. 7 No. 3, pp. 209-216.

Kumar, M., Vrat, P. and Shankar, R. (2004), “A fuzzy goal programming approach for vendor selection problem in a supply chain”, Computers \& Industrial Engineering, Vol. 46 No. 1, pp. 69-85.

Kwong, C. K., Ip, W. H. and Chan, J. W. K. (2002), "Combining scoring method and fuzzy expert systems approach to supplier assessment: a case study", Integrated Manufacturing Systems, Vol. 13 No. 7, pp. 512-519.

Lasch, R. and Janker, C. G. (2005), "Supplier selection and controlling using multivariate analysis", International Journal of Physical Distribution \& Logistics Management, Vol. 35 No. 6, pp. 409-425.

Lin, C. W. R. and Chen, H. Y. S. (2004), “A fuzzy strategic alliance selection framework for supply chain partnering under limited evaluation resources”, Computers In Industry, Vol. 55 No. 2, pp. 159179 . 
Liu, J., Ding, F. Y. and Lall, V. (2000), "Using data envelopment analysis to compare suppliers for supplier selection and performance improvement”, Supply Chain Management: An International Journal, Vol. 5 No. 3, pp. 143-150.

Liu, F. F. and Hai, H. L. (2005), "The voting analytic hierarchy process method for selecting supplier”, International Journal of Production Economics, Vol. 97 No. 3, pp. 308-317.

Ohdar, R. and Ray, P. K. (2004), "Performance measurement and evaluation of suppliers in supply chain: an evolutionary fuzzy-based approach", Journal of Manufacturing Technology Management, Vol. 15 No. 8, pp. 723-734.

Ross A. and Droge, C. (2002), "An integrated benchmarking approach to distribution center performance using DEA modeling”, Journal of Operations Management, Vol. 20 No. 1, pp. 19-32.

Sha, D. and Che, Z. (2006), "Supply chain network design: partner selection and production/distribution planning using a systematic model”, Journal of the Operational Research Society, Vol. 57 No. 1, pp. 52-62.

Shin, H., Collier, D. A. and Wilson, D. D. (2000), "Supply management orientation and supplier/buyer performance”, Journal of Operations Management, Vol. 18 No. 3, pp. 317-333.

Smirlis, Y. G., Maragos, E. K. and Despotis, D. K. (2006), "Data envelopment analysis with missing values: an interval DEA approach”, Applied Mathematics and Computation, Vol. 177 No. 1, pp. 1-10.

Talluri, S. and Baker, R. C. (2002), “A multi-phase mathematical programming approach for effective supply chain design”, European Journal of Operational Research, Vol. 141 No. 3, pp. 544-558.

Talluri, S. and Narasimhan, R. (2003), "Vendor evaluation with performance variability: a max-min approach”, European Journal of Operational Research, Vol. 146 No. 3, pp. 543-552.

Talluri, S., Narasimhan, R. and Nair, A. (2006), "Vendor performance with supply risk: a chanceconstrained DEA approach”, International Journal of Production Economics, Vol. 100 No. 2, pp. 212222.

Vokurka, R. J., Choobineh, J. and Vadi, L. (1996), “A prototype expert system for the evaluation and selection of potential suppliers”, International Journal of Operations \& Production Management, Vol. 16 No. 12, pp. 106-127.

Wang, Y. M., Greatbanks, R. and Yang, J. B. (2005), "Interval efficiency assessment using data envelopment analysis”, Fuzzy Sets and Systems, Vol. 153 No. 3, pp. 347-370.

Wang, G., Huang, S. H. and Dismukes, J. P. (2004), "Product-driven supply chain selection using integrated multi-criteria decision-making methodology", International Journal of Production Economics, Vol. 91 No. 1, pp. 1-15.

Weber, C. A. (1996), “A data envelopment analysis approach to measuring vendor performance”, Supply Chain Management, Vol. 1 No. 1, pp. 28-39.

Weber, C. A., Current, J. and Desai A. (2000), “An optimization approach to determining the number of vendors to employ”, Supply Chain Management: An International Journal, Vol. 5 No. 2, pp. 90-98. 
Xia, W. and Wu, Z. (2007), "Supplier selection with multiple criteria in volume discount environments”, Omega, Vol. 33 No. 5, pp. 494-504.

Youssef, M. A., Zairi, M. and Mohanty, B. (1996), "Supplier selection in an advanced manufacturing technology environment: an optimization model”, Benchmarking for Quality Management \& Technology, Vol. 3 No. 4, pp. 60-72. 